\title{
USING FLY ASH AS A PARTIAL REPLACEMENT FOR FINE AGGREGATE IN CONCRETE AND ITS EFFECTS ON CONCRETE PROPERTIES UNDER DIFFERENT CURING TEMPERATURES
}

\author{
Maliduwa Liyanage Chamini Surangi ${ }^{1}$, Parnthep Julnipitawong ${ }^{2 *}$, Somnuk \\ Tangtermsirikul $^{3}$, Yoshifumi $\mathrm{Ohgi}^{4}$, and Yusuke Ishii $^{5}$ \\ ${ }^{1}$ School of Civil Engineering and Technology, Sirindhorn International Institute of Technology, Thammasat \\ University, Thailand, e-mail: chaminisliyanage@gmail.com \\ ${ }^{2}$ Construction and Maintenance Technology Research Center, School of Civil Engineering and Technology, \\ Sirindhorn International Institute of Technology, Thammasat university, Thailand, \\ e-mail: parnthep@siit.tu.ac.th \\ ${ }^{3}$ School of Civil Engineering and Technology, Sirindhorn International Institute of Technology, Thammasat \\ University, Thailand, e-mail: somnuk@siit.tu.ac.th \\ ${ }^{4}$ Central Research Laboratory, Taiheiyo Cement Corporation, Japan, \\ e-mail: yoshifumi_ohgi@taiheiyo-cement.co.jp \\ ${ }^{5}$ Central Research Laboratory, Taiheiyo Cement Corporation, Japan, \\ e-mail: yusuke_ishii@taiheiyo-cement.co.jp
}

Received Date: August 2, 2019; Revised Date: February 18, 2019; Acceptance Date: April 20, 2020

\begin{abstract}
A shortage of natural fine aggregates has occurred worldwide, especially due to excessive consumption of them in construction activities. For this, the availability of sustainable alternative materials for natural fine aggregate is researched. Fly ash is identified as one such material that can partially replace fine aggregate in concrete. The current study demonstrates the feasibility of using fly ash as a partial fine aggregate replacing material in concrete and its effects on the compressive strength and some significant durability properties when cured under different curing temperatures. Fine aggregate and cement were partially replaced with Class $\mathrm{F}$ fly ash in different percentages. The curing methods (used in this study) were isothermal heat curing at $30^{\circ} \mathrm{C}, 50^{\circ} \mathrm{C}$, and $70^{\circ} \mathrm{C}$, and one-day accelerated heat curing. The compressive strength test, carbonation depth test, rapid chloride penetration test, and surface resistivity test were performed for concrete mixtures with different fly ash replacement levels and curing temperatures. Test results reveal that the use of fly ash as a partial fine aggregate replacing material in concrete gives higher compressive strength than that of concrete with fly ash as a partial cement replacing material at both an early age and a later age. One-day accelerated curing is the most beneficial curing method, regarding the compressive strength at all the tested ages. Moreover, concrete with fine aggregate replacement gives better results for carbonation resistance, chloride penetration resistance, and surface resistivity when compared with the control mixture and mixtures with fly ash as a partial cement replacing material.
\end{abstract}

Keywords: Compressive strength, Durability, Elevated temperature, Fine aggregate, Fly ash

\section{Introduction}

As the demand for concrete in the construction industry is rising day by day, a large amount of natural aggregates needs to be utilized in construction activities. Annually, about 30 billion tons of natural sand are extracted worldwide, particularly for construction [1]. Extensive mining in rivers and beaches causes floods and storm surges, which badly affects people's livelihoods. Asian countries intensively face this issue due to higher extraction rates. Hence, finding alternative materials that can reduce the consumption of natural 
resources may help sustainability. Researchers are interested in using materials such as crushed construction and demolition waste, crushed rock powder, fly ash, bottom ash, copper slag, steel slag as fine aggregates in concrete.

Limited studies have shown that fly ash is feasible for use as a partial replacement for fine aggregate in mortar and concrete. Siddique [2] observed a considerable enhancement in concrete strength by incorporating fly ash as a partial replacement for fine aggregate. The compressive strength of concrete building blocks has been modified by replacing fine aggregates with fly ash. It was found that those fly ash concrete blocks could be utilized successfully for sustainable construction. The highest compressive strength was recorded at a 20\% replacement level [3]. Ravina [4] found that when fine sand in concrete is partly replaced with fly ash, the compressive strength, especially at later ages, and elasticity modulus are higher than that of the control. Papadakis [5] investigated the effects of fly ash as a supplement in mortars, partly replacing the volume of either cement or fine aggregate. In aggregate replacement, compressive strengths higher than in cement-only mortar were encountered after only 14 days. In cement replacement, strength benefits were encountered after 91 days.

Elevated curing temperatures are used in precast concrete manufacturing, to gain a higher strength at an early age [6]. Manufacturers use different curing methods, such as heat curing at elevated temperatures and steam curing to fulfill their requirements. However, curing under elevated temperatures usually adversely affects the later-age strength and durability of cement-only concrete due to the developed high porosity. The inclusion of fly ash as a partial cement replacement can benefit precast concrete by increasing workability, some of the durability properties, and long-term compressive strength. It was found that the hydration reaction, and the pozzolanic reaction are significantly affected by the curing temperature. The onset of the pozzolanic reaction can be shifted to earlier ages by elevating the curing temperatures [7]. However, less consideration has been given by researchers to the performance of concrete with fly ash as a partial replacement for fine aggregate under elevated curing temperatures. Therefore, the main objective of the current study is to investigate the behavior of concrete with fly ash as a partial replacement for fine aggregate. The impact of fly ash on the strength and some durability properties when cured under different curing temperatures; i.e., isothermal heat curing at elevated temperatures and one-day accelerated heat curing, is also studied.

\section{Methodology}

OPC Type I was used in all tested mixtures. Japanese fly ash, conforming to ASTM Class $\mathrm{F}$ was used throughout this research for both cement replacement and fine aggregate replacement. The chemical and physical properties of the binders used in the tests are given in Table 1 and Table 2, respectively. River sand and crushed limestone, complying with ASTM C33, were used in all mixtures, as conventional fine and coarse aggregates, respectively. To control the initial slump of concrete to be within $12 \pm 2.5 \mathrm{~cm}$, a naphthalene-based water-reducing admixture was used in all concrete mixtures at different dosages during concrete mixing.

\section{Mix Proportions}

Mix proportion calculations were based on the ratio between the volume of the paste and the volume of voids of compacted aggregate phase $\left({ }^{\gamma}\right)$, water-to-binder ratio (w/b) and the replacement ratio of fly ash. Six mix proportions were tested. 
Table 1. Chemical Compositions of the Tested Binders

\begin{tabular}{lcc} 
Chemical Composition (\%) & OPC & Fly Ash \\
\hline $\mathrm{SiO}_{2}$ & 20.56 & 56.52 \\
$\mathrm{Al}_{2} \mathrm{O}_{3}$ & 5.45 & 25.33 \\
$\mathrm{Fe}_{2} \mathrm{O}_{3}$ & 3.09 & 5.24 \\
$\mathrm{CaO}$ & 64.5 & 3.56 \\
$\mathrm{MgO}$ & 1.39 & 0.91 \\
$\mathrm{Na} 2$ & 0.21 & 0.34 \\
$\mathrm{~K}_{2} \mathrm{O}$ & 0.45 & 1.04 \\
$\mathrm{SO}_{3}$ & 2.11 & 0.29 \\
Loss on ignition & 2.11 & 3.8 \\
Free lime & 0.6 & 0.1 \\
\hline
\end{tabular}

Table 2. Physical Properties of the Tested Binders

\begin{tabular}{lll} 
Physical Property & OPC & Fly Ash \\
\hline Blaine fineness $\left(\mathrm{cm}^{2} / \mathrm{g}\right)$ & 3610 & 3270 \\
Specific gravity & 3.16 & 2.27 \\
\hline
\end{tabular}

They consist of a reference mixture (without fly ash) with a w/b ratio of 0.6 , and five other mix proportions containing fly ash, as either cement replacing or sand replacing material or both. Cement was replaced by fly ash at $15 \%$ by weight. Fine aggregate was replaced with fly ash at percentages of $20 \%$ and $40 \%$. For partially replacing fine aggregate with fly ash, the weight of the fly ash (FAs) was calculated as a weight percentage of the initial binder content. It was converted to volume and added into the mixture by replacing a similar volume of sand in the mixture. Table 3 shows the calculated mix proportions used in this study. Although the water-to-binder ratio before partially replacing fine aggregate with fly ash was 0.6 in all cases, after partially replacing fine aggregate with fly ash, the actual water-to-binder ratios of the mixtures were changed. The actual water-to-binder ratios $\left(\mathrm{w} / \mathrm{b}_{\text {actual }}\right)$ are also given in Table 3.

Table 3. Mix Proportions Used in the Tests

\section{Mix Details}

Material Content $\left(\mathbf{k g} / \mathrm{m}^{3}\right)$

\begin{tabular}{|c|c|c|c|c|c|c|c|c|c|c|c|c|}
\hline Mix ID & $>$ & $\vec{k}$ & 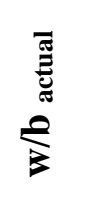 & 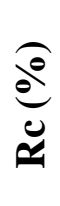 & 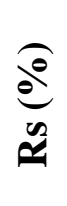 & 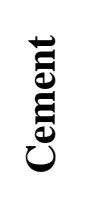 & $\sum_{x}^{0}$ & $\sum_{x}^{\infty}$ & $\frac{\grave{ \pm}}{\stackrel{\Xi}{*}}$ & 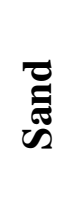 & 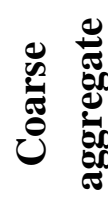 & 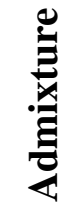 \\
\hline FCOFS0 & 1.2 & 0.6 & 0.60 & 0 & 0 & 277 & 0 & 0 & 166 & 857 & 1115 & 2.49 \\
\hline FCOFS20 & 1.2 & 0.6 & 0.50 & 0 & 20 & 277 & 0 & 55 & 166 & 794 & 1115 & 3.65 \\
\hline FC0FS40 & 1.2 & 0.6 & 0.43 & 0 & 40 & 277 & 0 & 111 & 166 & 731 & 1115 & 4.07 \\
\hline FC15FS0 & 1.2 & 0.6 & 0.60 & 15 & 0 & 231 & 41 & 0 & 163 & 857 & 1115 & 3.80 \\
\hline FC15FS20 & 1.2 & 0.6 & 0.50 & 15 & 20 & 231 & 41 & 54 & 163 & 795 & 1115 & 4.07 \\
\hline FC15FS40 & 1.2 & 0.6 & 0.43 & 15 & 40 & 231 & 41 & 109 & 163 & 734 & 1115 & 4.18 \\
\hline
\end{tabular}

Note: $\gamma$ is the ratio between the volume of the paste and the volume of voids of the compacted aggregate phase, $\mathrm{w} / \mathrm{b}$ is the initial water-to-binder ratio, $\mathrm{w} / \mathrm{b}$ actual is the actual water-to-binder ratio, $\mathrm{Rc}(\%)$ is the cement replacement percentage of fly ash by weight of the initial binder content, $\operatorname{Rs}(\%)$ is the fine aggregate replacement percentage of fly ash by weight of the initial binder content, FAc is the quantity of fly ash replacing cement $\left(\mathrm{kg} / \mathrm{m}^{3}\right)$, and FAs is the quantity of fly ash replacing sand $\left(\mathrm{kg} / \mathrm{m}^{3}\right)$. 


\section{Preparation and Curing Process of Specimens}

The concrete mixing method was conducted according to ASTM C192. Specimens were cast in 100-mm cubic molds. Just after casting, all the specimens together with the molds were covered with plastic sheets and aluminum foils on their top surfaces, in order to prevent moisture loss. Then they were stored in ovens, under controlled curing regimes. After 24 hours, they were taken out and demolded. After that, each of them was wrapped by 3 layers of aluminum foils and 3 layers of plastic sheets. Two heat-curing processes were adopted, which are isothermal heat curing and one-day accelerated heat curing.

\section{Isothermal Heat Curing}

The selected constant temperatures are $30^{\circ} \mathrm{C}, 50^{\circ} \mathrm{C}$, and $70^{\circ} \mathrm{C}$. Under this method, isothermal curing conditions were maintained throughout the curing period.

\section{One-Day Accelerated Heat Curing}

This curing method has been introduced to accelerate the early-age strength development. The one-day heat cycle with maximum temperature of $70^{\circ} \mathrm{C}$ used in this study is based on a previous study of Ho et al [8]. In this method, specimens were kept in an isothermal condition at $30^{\circ} \mathrm{C}$ for the first 3 hours immediately after casting. The curing cycle is completed within the first 24 hours after casting (see Figure 1). After this 24-hour curing, the specimens were kept in an isothermal condition at $30^{\circ} \mathrm{C}$ until the testing ages.

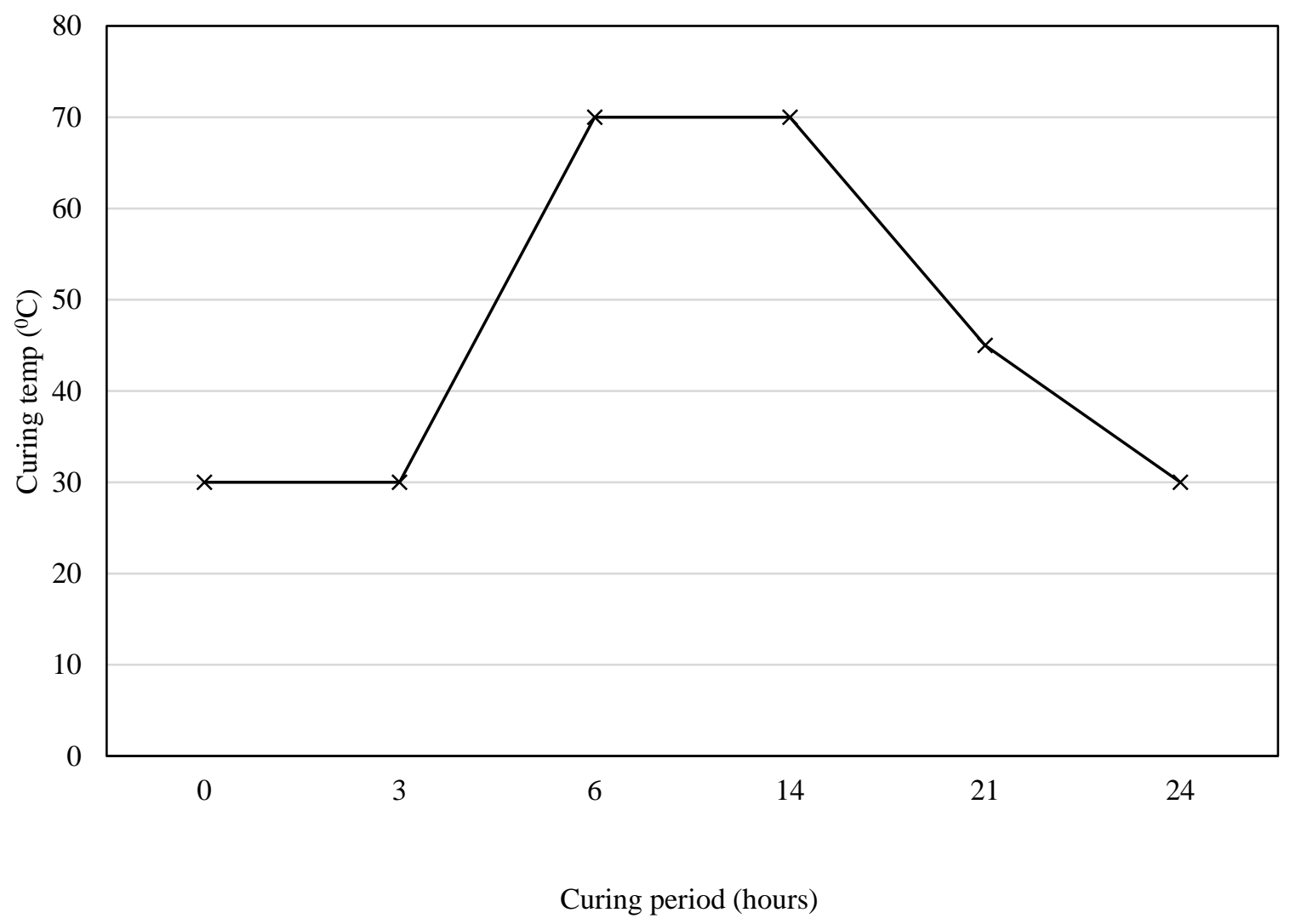

Figure 1. Temperature profile of the 1- day accelerated heat-curing method 


\section{Testing Methods}

\section{Compressive Strength Test}

Compressive strengths of samples cured under different curing regimes were tested at the ages of $1,3,7,28$, and 91 days as per ASTM C39. The cubic compressive strength was evaluated, and specimens were cast in plastic molds of 100x100x100 $\mathrm{mm}^{3}$. The average compressive strength for each mixture in each curing regime was obtained from 3 specimens.

\section{Carbonation Depth Test}

Cubic concrete specimens with dimensions of $100 \times 100 \times 100 \mathrm{~mm}^{3}$ were cast to test the carbonation depth. Samples were cured at different curing temperatures for 28 days. After the curing period, specimens were stored inside a chamber where the carbonation is accelerated with $4 \% \mathrm{CO}_{2}$ concentration, $40^{\circ} \mathrm{C}$ temperature, and $50 \pm 5 \%$ relative humidity, until the carbonation depth measuring age. The carbonation depth of samples was measured at 28 days and 91 days of exposure. The carbonation depth was observed by sprinkling a solution of phenolphthalein on the freshly broken concrete surface. The mean depth of carbonation was recorded from twelve readings per one sample, by measuring three times from each side of the broken surface. Three samples, at each age, under each curing scheme, were evaluated for the average carbonation depth.

\section{Rapid Chloride Penetration Test}

Specimens for the rapid chloride penetration test (RCPT) were cast in steel cylindrical molds of 100-mm diameter and 200-mm height and kept curing under each curing regime for the first 28 days. Thereafter, all the specimens were cured under the same conditions at $30^{\circ} \mathrm{C}$ until the testing age. At the ages of 28 days and 91 days, the RCPT was carried out as per ASTM C1202 (2012). In the test, the amount of electrical charge, passed during a six-hour period through 2-inch-thick slices cut from cylindrical specimens, was evaluated. One side of the specimen was connected with a solution of sodium chloride and the other with a solution of sodium hydroxide. The potential difference between the two ends was maintained at $60 \mathrm{~V} \mathrm{DC}$. The total charge passed was calculated, accordingly. Three specimens were tested to get an average for each test case.

\section{Surface Resistivity}

The surface resistivity of the samples was measured using a Wenner array probe, at the ages of 28 and 91 days as per AASHTO TP95 (2014). Cylindrical specimens of 100-mm diameter and 200-mm height were used in the test. Curing ages for the surface resistivity test are similar to those of the RCPT. Before testing, the concrete surface was made to be nearly saturated surface dry (SSD), using a wet piece of cloth. The Wenner probe was held longitudinally on the curved surface of the sample and pressed for 10-20 seconds, and the reading was recorded. For each specimen, the resistivity was measured at four locations which were apart from each other. The concrete specimen was put on an insulating surface while measuring the resistivity. An average of 2 samples was used as the surface resistivity of the tested samples in each case.

\section{Summary of Testing}

Figure 2 gives the summary of specimen preparation and testing ages of concrete specimens for compressive strength and durability tests, starting from the time of mixing concrete. The compressive strength of concrete specimens were tested at the ages of 1, 3, 7, 28 and 91 days for all of curing regimes. Carbonation depth was tested at the ages of 56 and 119 days. Both RCPT and surface resistivity were tested at the ages of 28 and 91 days. It is noted that concrete specimens were cured under specified curing regimes before beginning all durability tests. 


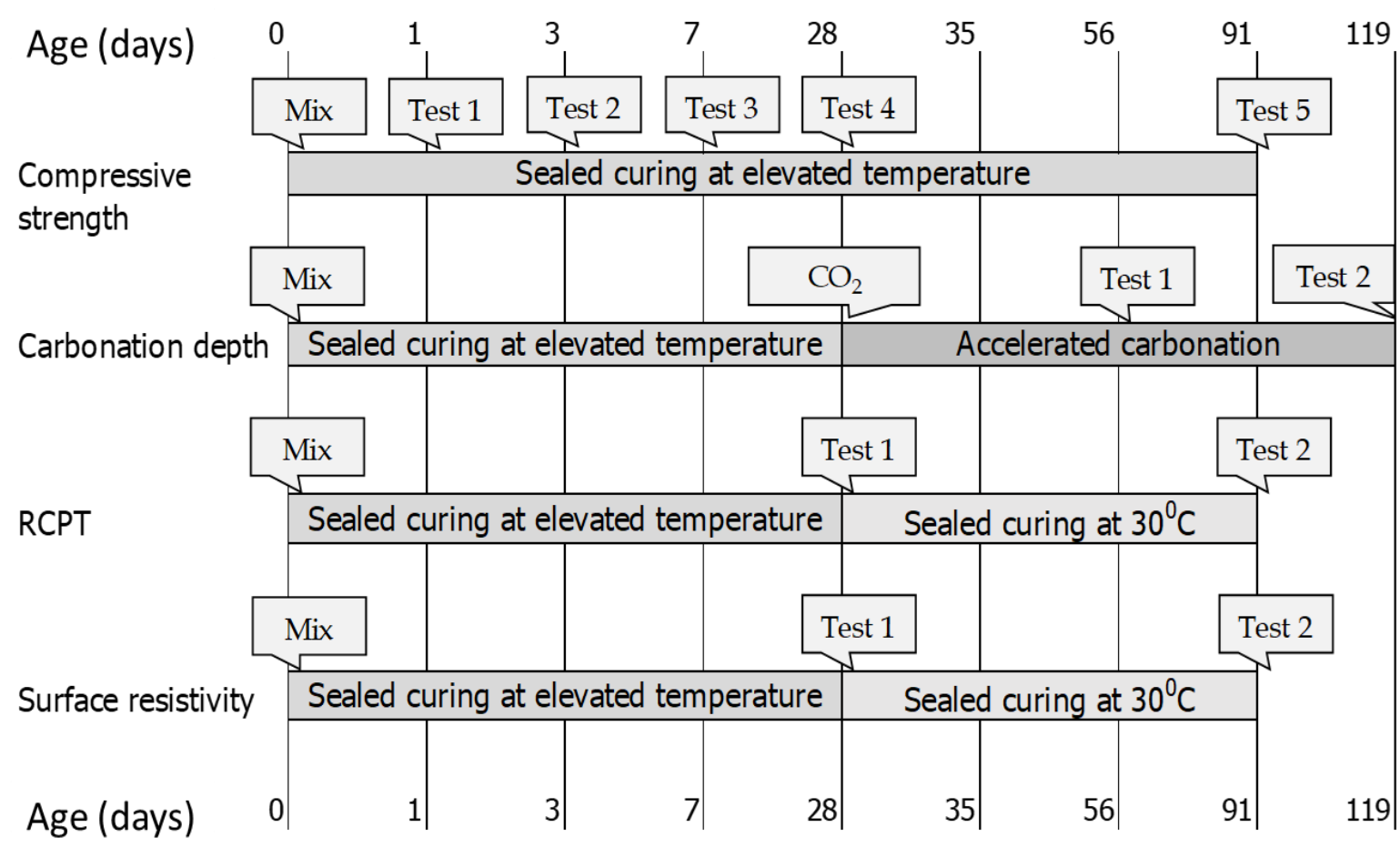

Figure 2. Specimen preparation and testing ages for each test

\section{Results and Discussion}

\section{Compressive Strength}

Figure 3 shows the compressive strength values of all mixtures, cured under isothermal curing at $30^{\circ} \mathrm{C}$. At an early age (up to 7 days), the compressive strength of mixtures having fly ash as a partial cement replacement (FC15FS0, FC15FS20, FC15FS40) shows lower compressive strengths than mixtures without fly ash as a partial cement replacement (FCOFS0, FCOFS20, FCOFS40), respectively. This is due to dilution, causing a lower hydration reaction at an early age as some cement content is replaced, and a slow pozzolanic reaction of mixtures in which the fly ash is incorporated as cement replacement [9]. However, at 28 and 91 days, mixtures having fine aggregate replacement ratios of $20 \%$ and $40 \%$ (with or without a cement replacement ratio of $15 \%$ ) obtained higher compressive strengths, compared to FCOFS0 and FC15FS0. This is more obvious at the age of 91 days than at 28 days. In Figure 3, it can be seen that with the increase in the fine aggregate replacement percentage from $0 \%$ to $20 \%$ and $40 \%$, the compressive strength gain is higher. The highest compressive strength values of 18.53 , $29.82,34.71,47.84$, and $52.36 \mathrm{MPa}$ at the ages of 1, 3, 7, 28, and 91 days, respectively, are obtained from the mixture with $40 \%$ sand replacement (FC0FS40). This shows that unlike in the case of cement replacement, concrete with fly ash as a partial sand replacement gives higher compressive strength than the control (no-fly ash) mixture (FCOFS0) at both an early age and a later age. This is a result of the pozzolanic reaction and densification of the concrete matrix when fly ash is used to partially replace sand, as explained by Siddique [2]. The space between the interface of fine and coarse aggregates can be filled with fine fly ash particles. This reduces the entrapped air in the mixture as well. This leads to the densification of the mixture, and hence, the compressive strength is improved. 


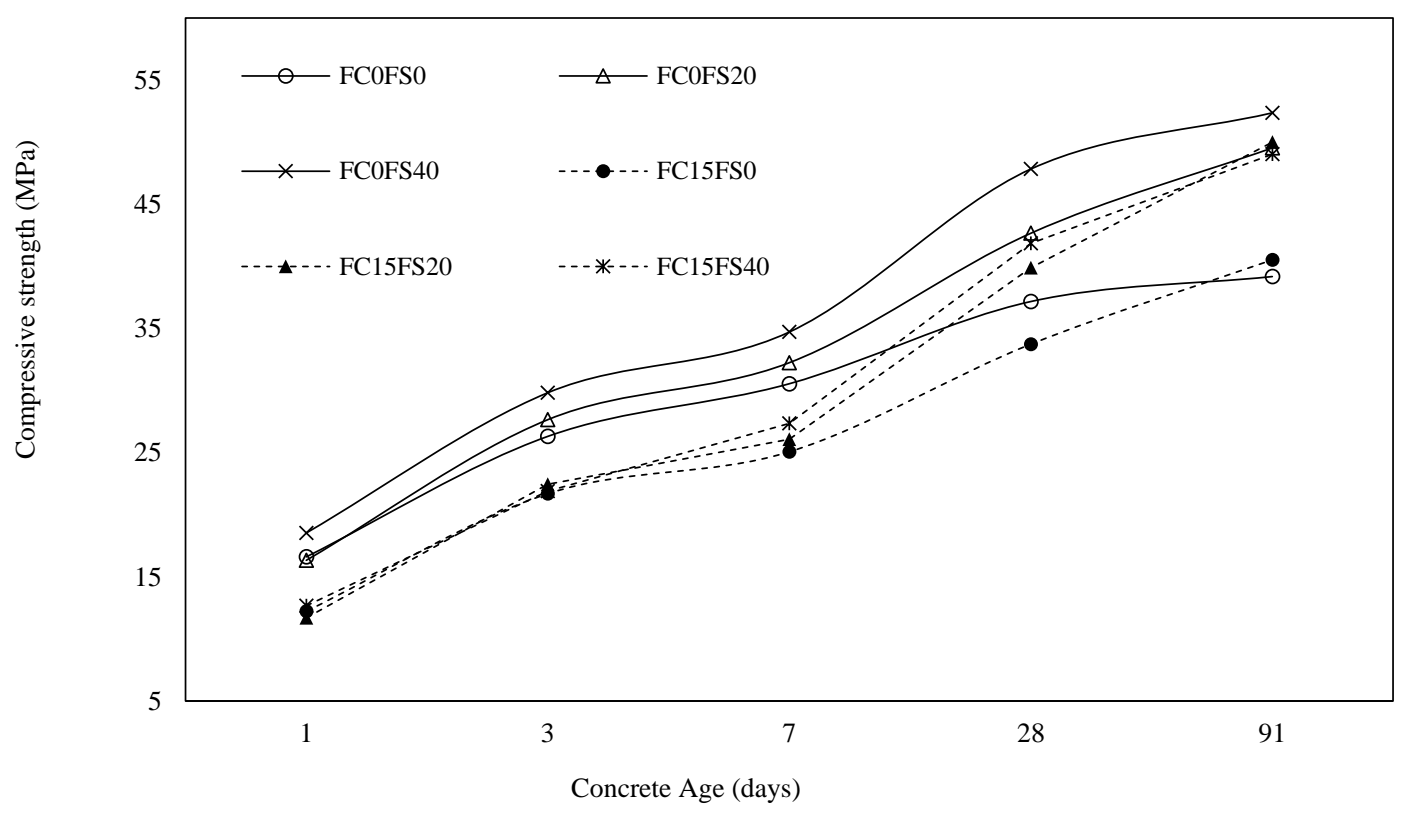

Figure 3. Compressive strength of concrete with curing temperature of $30^{\circ} \mathrm{C}$

Heat-curing efficiencies of all the mixtures cured under different curing temperatures are shown in Figure 4. In this study, the percentage of compressive strength of concrete that was cured at elevated temperatures, compared to that of the same mixture of concrete cured at $30^{\circ} \mathrm{C}$ at each age, is referred to as the heat-curing efficiency. The heat-curing efficiency can be computed from equation (1), in which $\mathrm{f}^{\prime} \mathrm{c}(\mathrm{T}, \mathrm{t})$ and $\mathrm{f}^{\prime} \mathrm{c}\left(30^{\circ} \mathrm{C}, \mathrm{t}\right)$ refer to the compressive strength of specimens cured at each curing temperature, $\mathrm{T}\left({ }^{\circ} \mathrm{C}\right)$, and the compressive strength of specimens of the same concrete cured under $30^{\circ} \mathrm{C}$ at the same age, $\mathrm{t}$ (days), respectively.

$$
\text { Heat curing efficiency }=\frac{f^{\prime} c(T, t)}{f^{\prime} c\left(30^{\circ} c, t\right)}
$$

For the curing temperatures of $50^{\circ} \mathrm{C}$ and $70^{\circ} \mathrm{C}$, the compressive strength is enhanced significantly at the age of 1 day, compared to that of concrete cured at $30^{\circ} \mathrm{C}$ in all cases (see Figure 4). The same behavior was observed by Verbeck and Helmuth [10]. This is due to the acceleration of the hydration reaction under high temperature. However, the efficiency of the curing temperature on the compressive strength gradually decreases with age. Ultimately at 91 days, elevated curing temperatures $\left(50^{\circ} \mathrm{C}\right.$ and $\left.70^{\circ} \mathrm{C}\right)$ result in a lower compressive strength than the normal curing temperature of $30^{\circ} \mathrm{C}$ in all cases. This reduction of later-age strength is as a result of the formation of more porous products during the rapid hydration reaction under elevated curing temperatures [10]. Too high a curing temperature is not favorable for the later-age strength development of concrete.

By comparing Figure 4(a) with Figures 4(b) to 4(f), it is clear that the compressive strengths of fly ash concrete are more sensitive to the curing temperature than the cementonly concrete, especially at an early age. This is caused by the sensitivity to a high temperature of the pozzolanic reaction of fly ash in concrete containing fly ash. Moreover, it is noted that elevated curing temperatures drastically enhance the early-age compressive strength of concrete, in which fly ash is included as both cement replacing and sand replacing material (Figures 4(e) and 4(f)). For instance, in FC15FS40, the heat-curing efficiency at 1 day is nearly $200 \%$ in the samples cured a $70^{\circ} \mathrm{C}$ (Figure $4(\mathrm{f})$ ). 
One-day accelerated curing results in high heat-curing efficiency at an age of 1 day which is nearly equal to that from $70^{\circ} \mathrm{C}$ in each case (see Figures 4(a) to 4(f)). The difference of long-term compressive strength values (at 91 days) of concrete cured under the 1-day accelerated curing method and isothermal curing at $30^{\circ} \mathrm{C}$ is insignificant when considering the overall behavior of the tested mixtures, as seen in Figures 4(a) to 4(f). These differences are in the range of $2-5 \%$ in all cases. Thus, it can be concluded that when considering overall behavior, the 1day accelerated curing is the most useful curing method for all mixtures for both early-age and later-age compressive strength improvement.

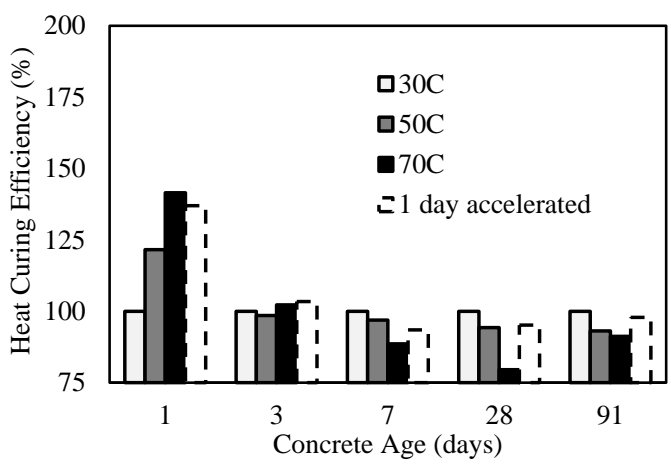

(a) $\mathrm{FCOFS0}$

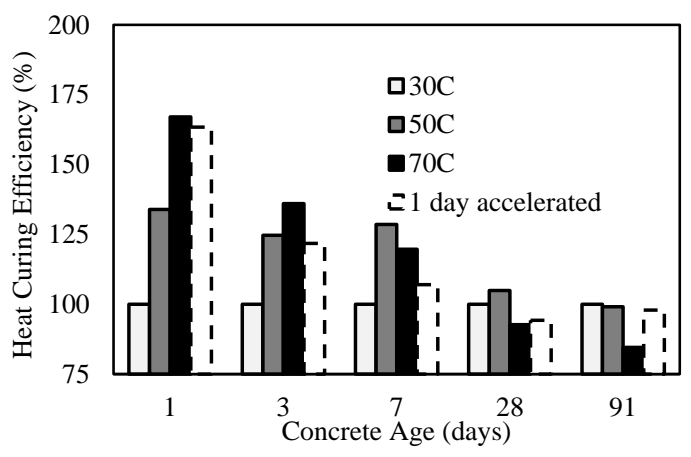

(c) FCOFS40

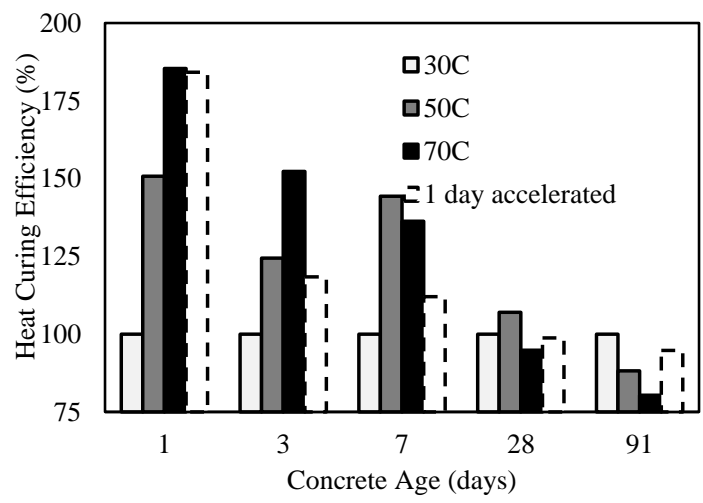

(e) FC15FS20

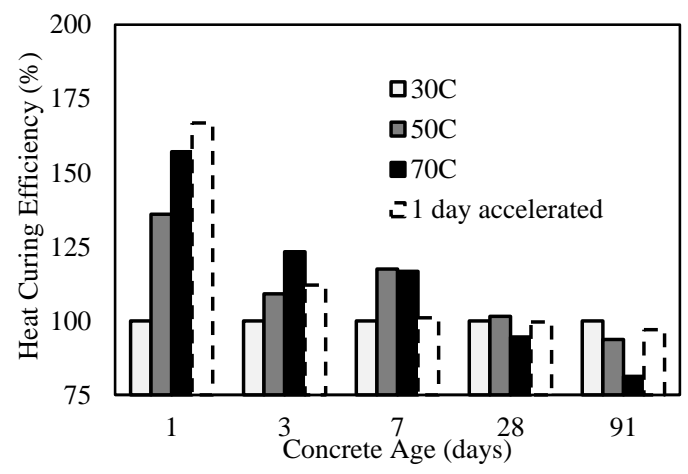

(b) FCOFS20

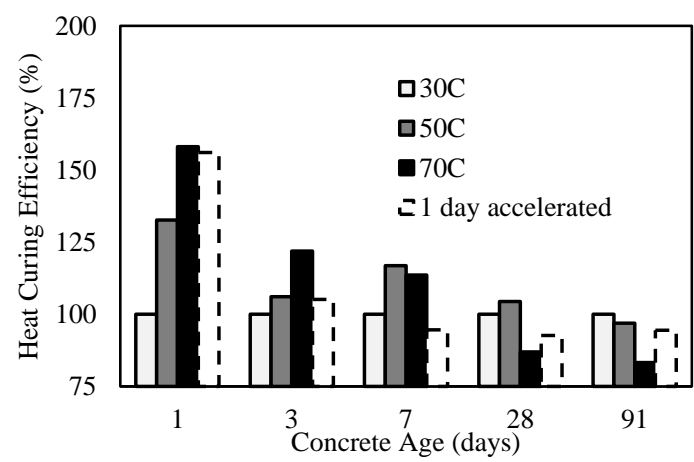

(d) FC15FS0

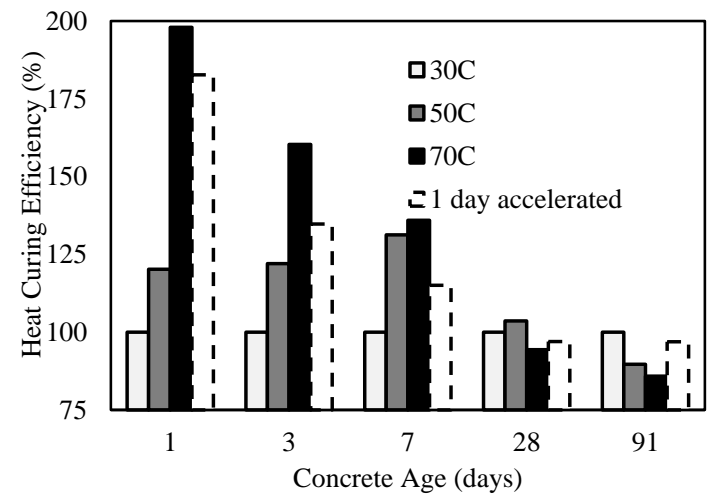

(f) $\mathrm{FC} 15 \mathrm{FS} 40$

Figure 4. Heat-curing efficiency of concrete, cured at different temperature

\section{Carbonation Depth}

When fly ash is incorporated into concrete at $20 \%$ fine-aggregate replacement (FCOFS20), the carbonation depth is reduced when compared to a cement-only mixture (see Figure 5 and Figure 6), similarly to that observed by Papadakis [11]. However, a further increase of the fine aggregate 
replacement percentage to $40 \%$ (in FCOFS40) shows an increase in the carbonation depth when compared to the $20 \%$ replacement of fine aggregate under each curing temperature, at a 28 -day exposure and a 91-day exposure (Figure 5 and Figure 6, respectively). Accordingly, the minimum carbonation depth at 28 and 91 days of exposure was recorded from the mixture with $20 \%$ fly ash for sand replacement (FCOFS20). Fly ash in concrete increases the carbonation depth due to the reduction of alkalinity in the mixture. Low actual water-to-binder ratios of mixtures with fly ash as a fine aggregate result in low carbonation depth. A combination of these effects makes FCOFS20 the mixture with the lowest carbonation depth.

Higher depths of carbonation are observed from the cases that use fly ash as $15 \%$ cement replacement when compared to the cases of concrete without cement replacement at 28day and 91-day exposures (by comparing the first 3 mixtures with the rest of the 3 mixtures in Figure 5 and Figure 6, under each curing temperature). Partly replacing cement with fly ash reduces the carbonation resistance, mainly due to lowered alkalinity as described by Tangtermsirikul [12]. Therefore, it is clear that although using fly ash as a partial replacement for cement reduces the carbonation resistance with respect to that of a cement-only mixture, using fly ash as a partial replacement for fine aggregate (not in high percentages) increases the carbonation resistance, compared to a cement-only mixture.

As the curing temperature increases from $30^{\circ} \mathrm{C}$ to $50^{\circ} \mathrm{C}$ and $70^{\circ} \mathrm{C}$, the carbonation depth shows a gradual increase in all the cases, except for a 91-day exposure of FC0FS20, FCOFS40, and FC15FS40 mixtures (see Figure 5 and Figure 6). However, the largest carbonation depth was observed from $70^{\circ} \mathrm{C}$ curing in all cases, showing that high curing temperatures reduce the carbonation resistance. Under elevated curing temperatures, coarser pore structures that cause a higher permeability are formed ([8], [13]). This may be the reason for the increasing carbonation depth with an increase in the curing temperature. One-day accelerated curing yields a lower carbonation depth than that by isothermal curing for the first 3 mixtures, in which fly ash is not incorporated as cement replacement (Figure 5 and Figure 6). However, for the rest of the 3 mixtures, in which fly ash is incorporated as $15 \%$ cement replacement, curing at a constant temperature of $30^{\circ} \mathrm{C}$ shows better resistance than that from the 1-day accelerated curing. Moreover, concrete cured under 1-day accelerated curing shows higher carbonation resistance than that cured at $50^{\circ} \mathrm{C}$ and $70^{\circ} \mathrm{C}$ in all the mixture cases, except for FC15FS40 at a 91-day exposure. Deogekar et al. [14] show that in accelerated curing, the delay prior to the direct exposure to high temperature brings beneficial effects for the durability properties of concrete. This supports the results that the specimens under the 1-day accelerated curing method show lower carbonation depths than those cured at constant elevated temperatures.

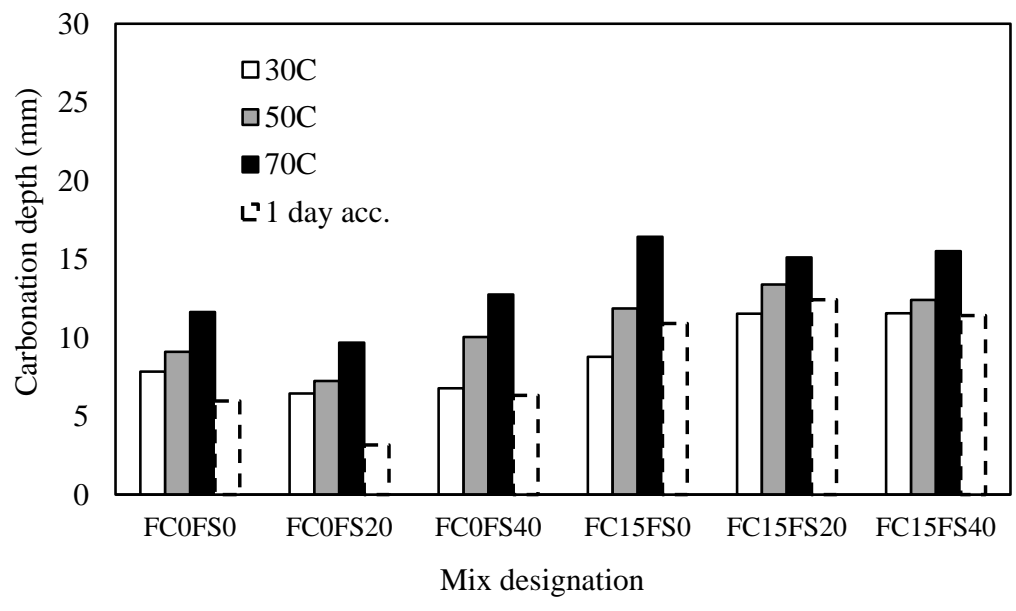

Figure 5. Carbonation depth at 28-day exposure 


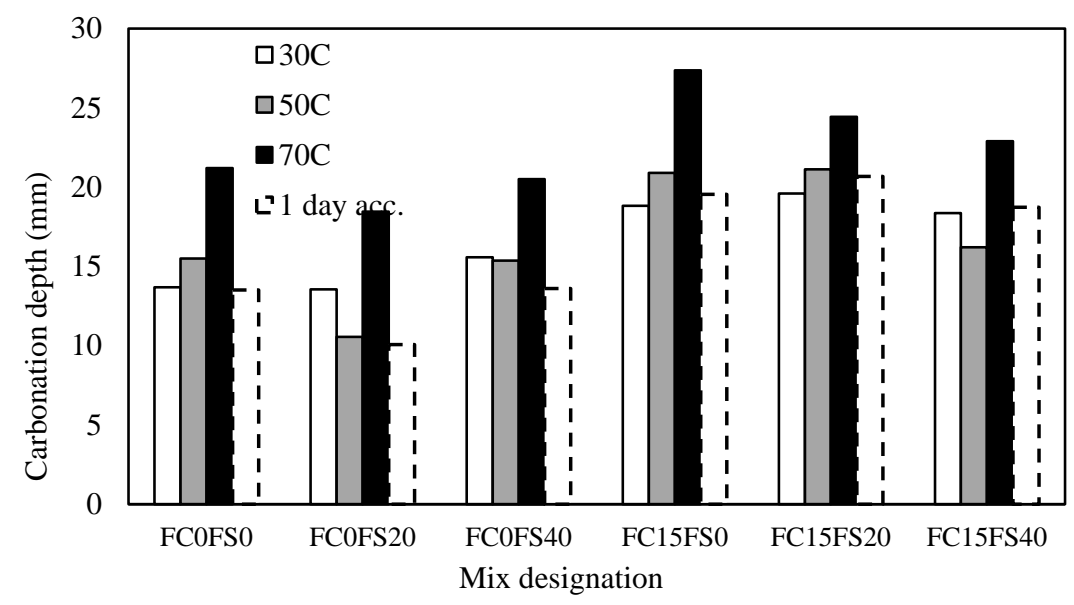

Figure 6. Carbonation depth at 91-day exposure

\section{Rapid Chloride Penetration}

When fly ash is incorporated as a cement or a sand replacing material, the chloride penetration at 28 and 91 days is significantly reduced compared to the reference mixture (FCOFS0) under all tested curing temperatures (see Figure 7 and Figure 8). With the increased fly ash percentage in concrete, the RCPT value is generally decreased. Ultimately, the chloride penetrability level of FC15FS40 concrete, which incorporates fly ash as both cement and sand replacements, (the mixture with the highest total fly ash content), shows the lowest chloride penetrability levels under all curing temperatures at the ages of 28 days and 91 days (Figure 7 and Figure 8). The RCPT results of FC15FS40 are only 13\% and 7\% of those of the cement-only mixture, cured at $30^{\circ} \mathrm{C}$, at the ages of 28 days and 91 days, respectively. The studies by Ramezanianpour and Malhotra [16] show that using fly ash as a partial replacement for cement in concrete increases the resistance to chloride penetration. This is due to the pozzolanic reaction of fly ash [17]. There are only few papers that discuss the chloride penetration in concrete with fly ash as a fine aggregate replacing material. They demonstrate that higher sand replacing percentages (by fly ash) increase the chloride penetration resistance [11].

As observed in Figure 7, concrete cured under elevated curing temperatures of $50^{\circ} \mathrm{C}$ and $70^{\circ} \mathrm{C}$ show better chloride penetration resistance at 28 days, as compared to that of concrete cured at $30^{\circ} \mathrm{C}$, except for FCOFS0 concrete that was cured at $70^{\circ} \mathrm{C}$. Acquaye [15] and Ramezanianpour and Malhotra [16] explain that concrete cured at elevated temperatures is more matured. Therefore, it has a higher resistance to chloride penetration when compared to concrete that was cured at a normal temperature. However, when considering the 91-day results, concrete cured at $70^{\circ} \mathrm{C}$ shows higher penetration than concrete cured at $30^{\circ} \mathrm{C}$ and $50^{\circ} \mathrm{C}$ for FCOFS0, FCOFS20, FC0FS40, and FC15FS20 (see Figure 8). Although curing at a high temperature produces more matured and less permeable concrete when compared to curing at a normal temperature at early ages, it produces more permeable concrete at later ages. In other words, high-temperature curing increases the strength development at an early age, but the later age strength could be slightly lower when compared to the normal curing temperature. At a later age, the porosity of concrete that is cured at a high temperature is higher than that of concrete cured at a normal temperature. By considering all the curing conditions, the lowest penetration was observed for curing at $50^{\circ} \mathrm{C}$ in all mix proportions at both 28 days and 91 days (see Figure 7 and Figure 8). According to Tang et al. [18], 60 ${ }^{\circ} \mathrm{C}$ curing recorded the minimum chloride ion permeability among the curing temperatures of $30^{\circ} \mathrm{C}, 60^{\circ} \mathrm{C}$, and $90^{\circ} \mathrm{C}$, tested at an age of 28 days. This confirms the earlier explanation that 
curing at high temperatures makes concrete more matured and less permeable at early ages but more permeable at later ages. In contrast, according to Detwiler et al. [13], at later ages, concrete cured at a normal temperature shows higher resistance to chloride penetration than concrete cured at an elevated temperature as the concrete is fully hydrated. However, concrete specimens cured under the one-day accelerated curing method demonstrate higher chloride penetration than concrete cured at $30^{\circ} \mathrm{C}$ and $50^{\circ} \mathrm{C}$. It is observed that when the fly ash replacement percentage (for both fine aggregate replacement and cement replacement) is higher, the 1-day accelerated curing method is more effective (see Figure 7 and Figure 8).

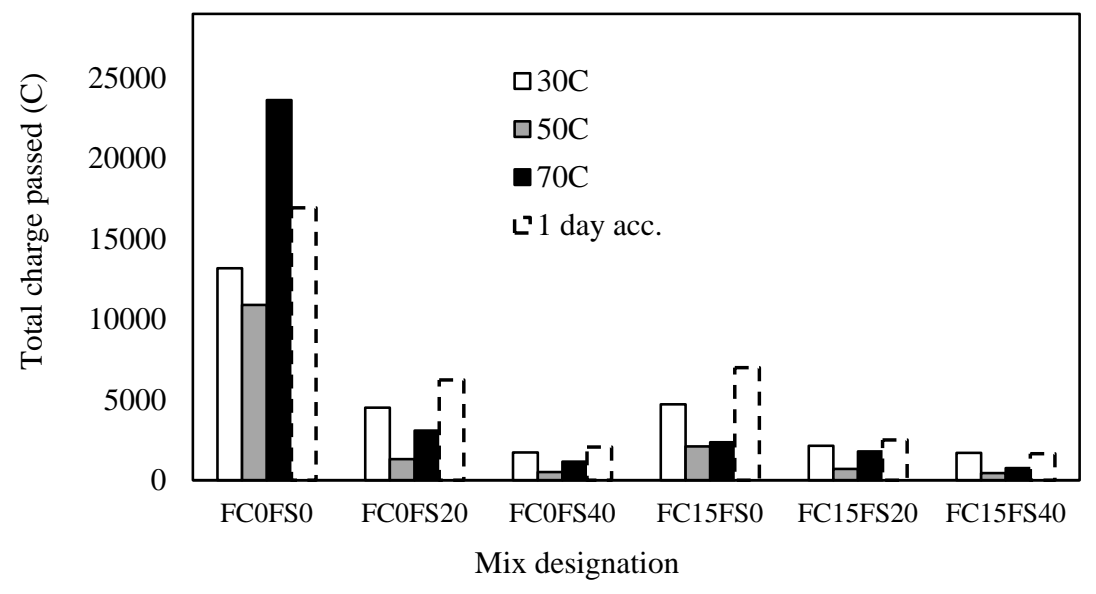

Figure 7. Rapid chloride penetration at 28 days

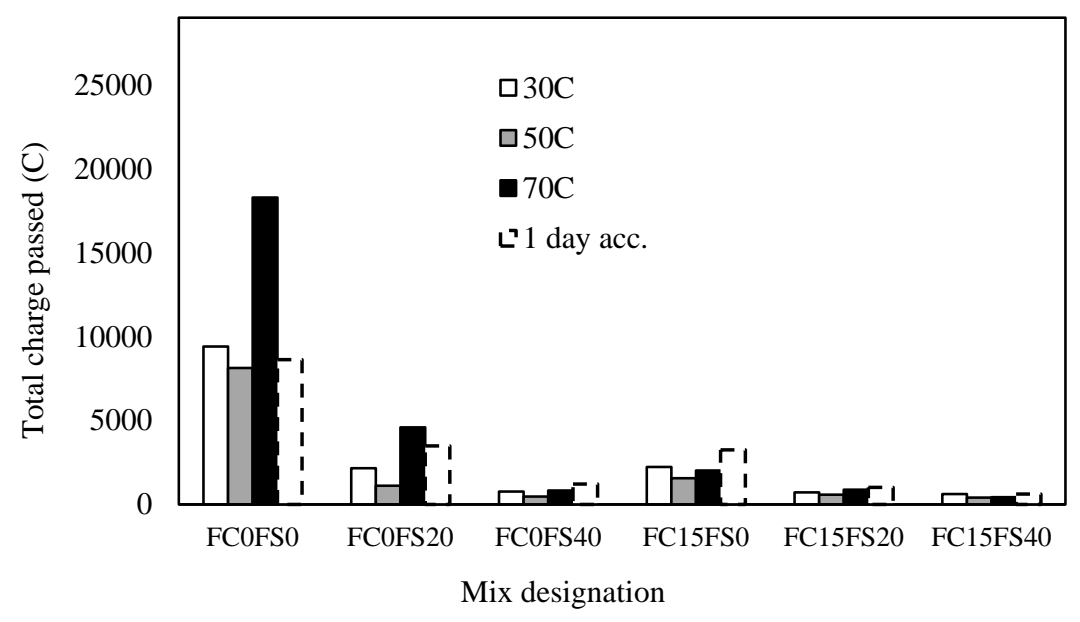

Figure 8. Rapid chloride penetration at 91 days

\section{Surface Resistivity}

When fly ash is incorporated as cement replacement at a rate of $15 \%$, the surface resistivity is higher when compared to the reference mixture (see Figure 9 and Figure 10). When increasing the replacement percentage of fly ash as fine aggregates from $0 \%$ to $40 \%$, the resistivity is increased at 28 days, as shown in Figure 9. Higher fly ash replacement either as sand replacement or cement replacement results in higher resistivity. Acquaye [15] observed that the resistivity of concrete increase as the fly ash replacement percentage is increased under different curing conditions. At the age of 91 days, fly ash concrete with $20 \%$ fine aggregate replacement (FC15FS20) has higher resistivity than concrete with $40 \%$ replacement (FC15FS40). 
From the three constant curing temperatures, $50^{\circ} \mathrm{C}$ gives the highest resistivity in all cases, except for FC15FS40 at 91 days (see Figure 9 and Figure 10). However, according to Acquaye [15], fly ash concrete cured at $71^{\circ} \mathrm{C}$ had the highest resistivity among all samples cured at temperatures of $23^{\circ} \mathrm{C}, 71^{\circ} \mathrm{C}$, and $82^{\circ} \mathrm{C}$. Surface resistivity values of the samples cured under the 1-day accelerated method were lower than those cured at the normal curing temperature of $30^{\circ} \mathrm{C}$, except for FC15FS40 at the ages of 28 and 91 days. The behavior of surface resistivity under different curing temperatures is not clear. Future investigation is needed to clarify this behavior.

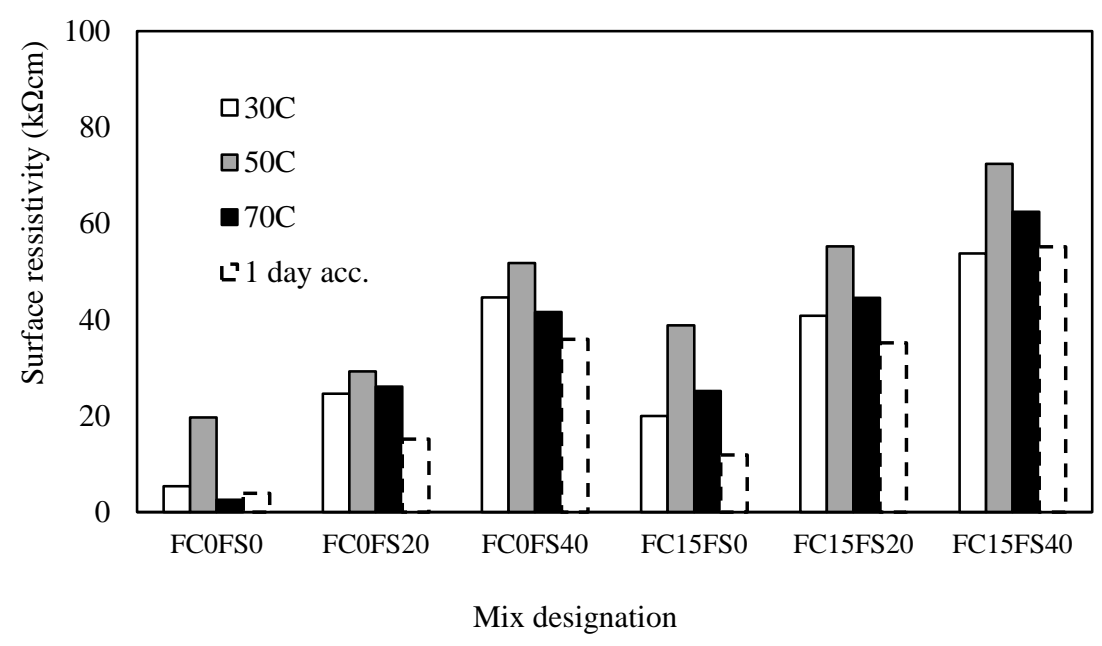

Figure 9. Surface resistivity at 28 days

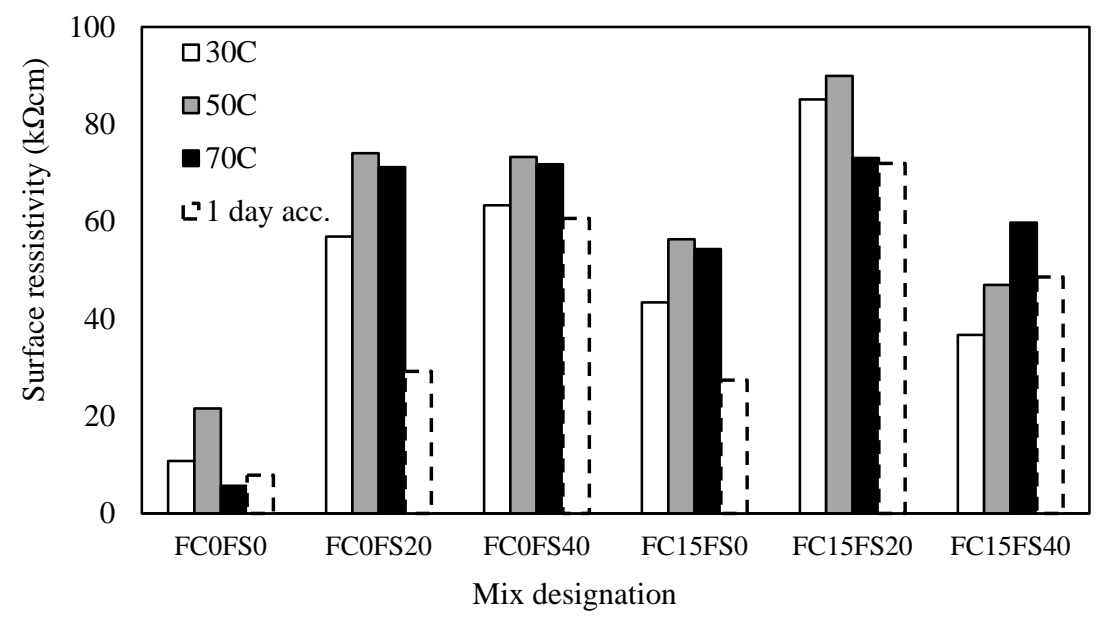

Figure 10. Surface resistivity at 91 days

\section{Relationship between Rapid Chloride Penetration and Surface Resistivity}

According to the classification of RCPT values and surface resistivity values as per ASTM C1202 and AASHTO TP95, when the chloride penetration is higher, the surface resistivity is lower. Similar behavior can be seen in the current study. The relationship between the RCPT values and the surface resistivity values obtained from all the mix proportions tested in the current study, cured under various curing temperatures, is shown in Figure 11. Thus, an equation could be derived to demonstrate the relationship between the total charge passed and the surface resistivity, as given in Equation (2). 
where $a$ is $2.71 \times 10^{4}$ and $b$ is -0.07 .

A similar correlation between the RCPT values and surface resistivity values of concrete was observed by Ramezanianpour et al. [19]. A few data points deviate above the average. These samples that have high RPCT values are those of the concrete without fly ash, which have the highest actual water-to-binder ratio (FCOFS0). This means that the chloride penetration (by charge passed) is probably more affected by the water-to-binder ratio or porosity of the mixtures than the surface resistivity. However, this hypothesis needs future investigations.

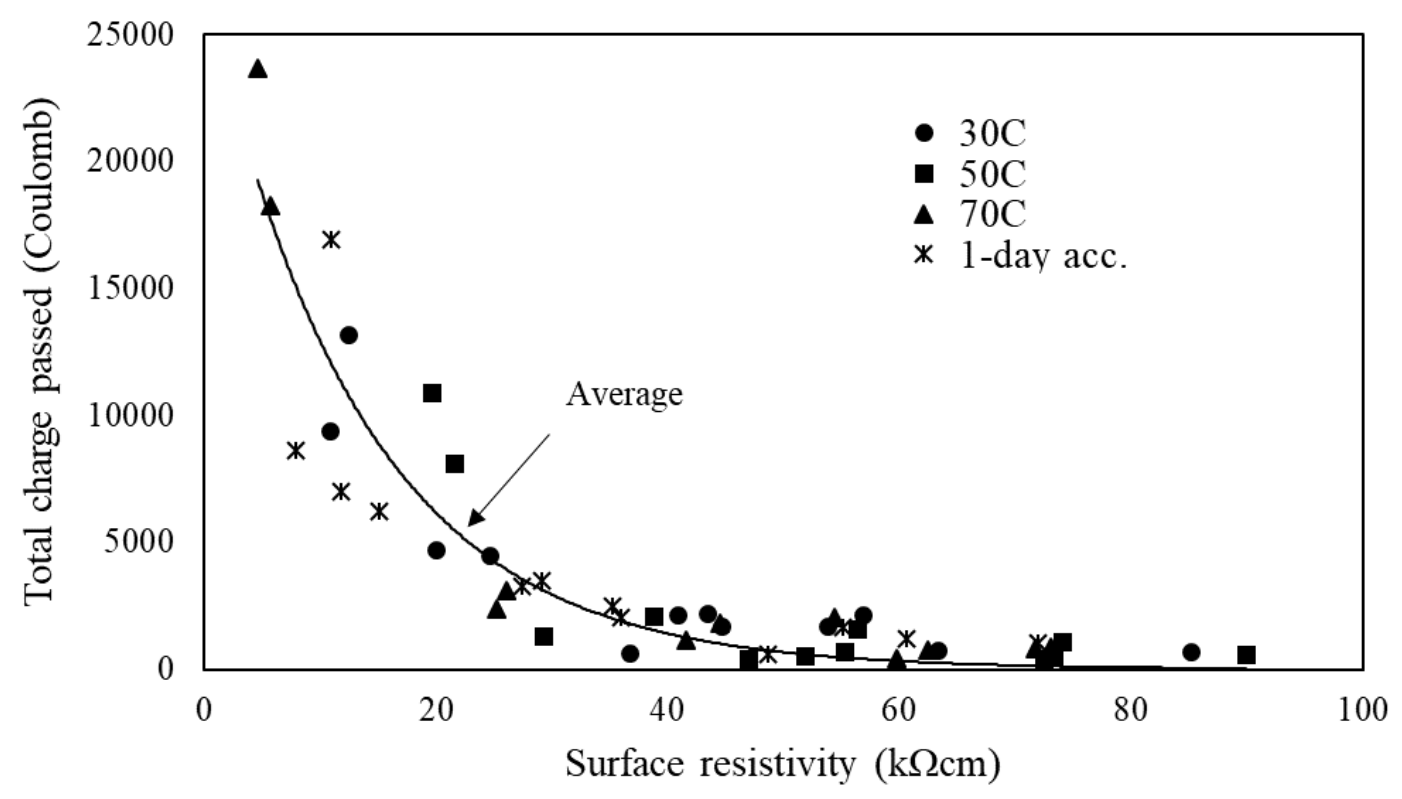

Figure 11. Relationship between total charge passed and surface resistivity

\section{Conclusions}

Concrete that incorporates fly ash as a partial fine aggregate replacement yields considerably higher compressive strength than cement-only concrete or concrete with fly ash as a cement replacement for both the short term and long term. When the fine aggregate replacement percentage is higher, the strength gain is higher. The highest fine aggregate replacement percentage, which is $40 \%$ in this study, records the highest compressive strength in almost all of the tested ages under all the tested curing temperatures. Concrete with fly ash as either partial cement replacement or fine aggregate replacement is more sensitive to curing temperature than cement-only concrete. At early ages, elevated curing temperatures (up to $70^{\circ} \mathrm{C}$ ) accelerate strength development. However, at later ages (28 to 91 days), curing at elevated temperatures results in lower compressive strength than curing at a normal temperature. Among the curing schemes studied, the one-day accelerated curing method is the most favorable (overall), considering both early-age and later-age compressive strengths.

Concrete with fly ash as $20 \%$ replacement for fine aggregate gives the highest carbonation resistance. As the curing temperature increases from $30^{\circ} \mathrm{C}$ to $50^{\circ} \mathrm{C}$ and $70^{\circ} \mathrm{C}$, the carbonation depth is increased. A significant reduction of rapid chloride penetration is seen in fly ash concrete, compared to cement-only concrete. Concrete containing the highest content of fly ash (15\% cement replacement and $40 \%$ sand replacement) shows the lowest 
chloride penetration. The lowest penetration was obtained by $50^{\circ} \mathrm{C}$ curing in all mix proportions. Enhanced surface resistivity is observed in concrete samples with fly ash when compared to cement-only concrete. Among all the curing temperatures considered, the highest resistivity is from the specimens cured isothermally at $50^{\circ} \mathrm{C}$. The relationship between the surface resistivity and the RCPT may require additional study.

\section{Acknowledgement}

The authors wish to acknowledge the Excellent Foreign Students (EFS) scholarship offered to the first author by the Sirindhorn International Institute of Technology (SIIT) of Thammasat University, Thailand, and the financial and material support given by Taiheiyo Cement Corporation, Japan.

\section{References}

[1] "Footprints in the Sand" (n.d.) [Online]. Available: https://www.worldcement.com/special-reports/16062015/footprints-in-the-sand-829/ [Accessed: August 2019]

[2] R. Siddique, "Effect of fine aggregate replacement with Class F fly ash on the mechanical properties of concrete," Cement and Concrete Research, Vol. 33, No. 4, pp. 539-547, 2003.

[3] R.V. Thomas, and D.G. Nair, "Fly ash as a fine aggregate replacement in concrete building blocks," International Journal of Engineering and Advanced Research Technology (IJEART), Vol. 1, No. 2, pp. 48-51, 2015.

[4] D. Ravina, "Mechanical properties of structural concrete incorporating a high volume of Class F fly ash as partial fine sand replacement," Materials and Structures, Vol. 31, pp. 84-90, 1998.

[5] V.G. Papadakis, "Effect of fly ash on Portland cement systems Part I. Low-calcium fly ash," Cement and Concrete Research, Vol. 29, No. 11, pp. 1727-1736, 1999.

[6] H.H. Patel, C.H. Bland, and A.B. Poole, "The Microstructure of concrete cured at elevated temperatures," Cement and Concrete Research, Vol. 25, No. 3, pp. 485490, 1995.

[7] M. Narmluk, and T. Nawa, "Effect of curing temperature on pozzolanic reaction of fly ash in blended cement paste," International Journal of Chemical Engineering and Applications, Vol. 5, No. 1, pp. 31-35, 2014.

[8] D.W.S. Ho, C.W. Chua, and C.T. Tam, "Steam-cured concrete incorporating mineral admixtures," Cement and Concrete Research, Vol. 33, No. 4, pp. 595-601, 2003.

[9] L. Lam, Y.L. Wong, and C.S. Poon, "Degree of hydration and gel/space ratio of highvolume fly," Cement and Concrete Research, Vol. 30, No. 5, pp. 747-756, 2000.

[10] G.J. Verbeck, and R.A. Helmuth, "Structures and physical properties of cement paste," In 4th International Symposium on the Chemistry of Cement, Symposium conducted in Tokyo, 1968.

[11] V.G. Papadakis, "Effect of supplementary cementing materials on concrete resistance against carbonation and chloride ingress," Cement and Concrete Research, Vol. 30, No. 2, pp. 291-299, 2000.

[12] S. Tangtermsirikul, Durability and Mix Design of Concrete, $1^{\text {st }}$ Edition, Printing House of Thammasat University, Pathumthani, Thailand, 2003.

[13] R.J. Detwiler, K.O. Kjellsen, and O.E. Gjorv, "Resistance to chloride intrusion of concrete cured at different temperatures," ACI Materials Journal, Vol. 88, No. 1, pp. 19-24, 1991. 
[14] P. Deogekar, A. Jain, S. Mishra, and, P. Nanthagopalan, "Influence of steam curing cycle on compressive strength of concrete," International Journal of Construction Materials and Structures, Vol. 1, pp. 18-28, 2013.

[15] L. Acquaye, Effect of High Curing Temperatures on the Strength, Durability and Potential of Delayed Ettringite Formation in Mass Concrete Structures, Thesis (PhD), University of Florida, Graduate School, United States, 2006.

[16] A.A. Ramezanianpour, and V.M. Malhotra, "Effect of curing on the compressive strength, resistance to chloride-ion penetration and porosity of concretes incorporating slag, fly ash or silica fume," Cement and Concrete Composites, Vol. 17, No. 2, pp. 125-133, 1995.

[17] L. Tang, and L.O. Nilsson, "Chloride diffusivity in high strength concrete," Nordic Concrete, Vol. 11, No. 1, pp.162-170, 1992.

[18] Y. Tang, H. Su, S. Huang, C. Qu, and J. Yang, "Effect of curing temperature on the durability of concrete under highly geothermal environment," Advances in Materials Science and Engineering, Vol. 2017, No. 5, pp. 1-9, 2017.

[19] A.A. Ramezanianpour, A. Pilvar, M. Mahdikhani, and F. Moodi, "Practical evaluation of relationship between concrete resistivity, water penetration, rapid chloride penetration and compressive strength," Construction and Building Materials, Vol. 25, pp. 2472-2479, 2011. 